\title{
Analysis of acid-base balance as well as hematological and biochemical parameters in horses of combined driving discipline
}

\author{
R. Kupczyński and K. Śpitalniak \\ Department of Environment Hygiene and Animal Welfare, Wroclaw University of Environmental and Life \\ Sciences, Wrocław, Poland \\ Correspondence to: R. Kupczyński (robert.kupczynski@up.wroc.pl)
}

Received: 29 August 2014 - Accepted: 17 April 2015 - Published: 1 June 2015

\begin{abstract}
The aim of this study was to evaluate the effect of training on hematological and biochemical blood indices and acid-base balance as well as to attempt an assessment of the degree of driving horses' training based on examined parameters during the training cycle. The study was conducted on eight Polish Halfbred driving horses (aged 6-12 years). Each four-horse harness included two geldings and two mares. Blood was collected before and directly after training as well as after a $30 \mathrm{~min}$ recovery period. Blood samples were analyzed for hematological and biochemical parameters, as well as acid-base balance and glutathione peroxidase activity. The data were processed using a general linear model (ANOVA) procedure in Statistica v10. A significant $(P<0.01)$ post-exercise increase in heart rate and respiratory rate was noted. Changes $(P<0.01)$ in red blood cells (RBC), hemoglobin (HGB), glucose (GLU) and nonesterified fatty acids (NEFA) were observed after exercise. Correctness of the exercises affects the rate of recovery to rest values. The fastest recovery to the values of the rest period was noted in the case of RBC, HGB, LYM (lymphocytes), $\mathrm{TCO}_{2}$ (total carbon dioxide), $\mathrm{HCO}_{3}^{-}$(bicarbonate concentration), GLU and NEFA. Training load did not cause acid-base balance disturbance, with visible compensation during the recovery period (increase in $\mathrm{HCO}_{3}^{-}$and extracellular base excess (BE)). Changes in GPx activity were not confirmed statistically; however an increasing tendency was observed after training. Long-term exercises of driving horses cause significant lipomobilization. This study enables an evaluation and comparison of physical preparation to effort and intensity of driving horses' training. In the case of driving horses' training, there is a need to accept lower lactic acid (LA) $\left(<4 \mathrm{mmol} \mathrm{L}^{-1}\right)$ values in aerobic-anaerobic threshold interpretation.
\end{abstract}

\section{Introduction}

The physical effort and stress which horses experience during training differs depending on sporting discipline. Correct training aims to adapt a horse's body system to the changes occurring during intensive physical effort (Piccione et al., 2010; Trigo et al., 2010; Fazio et al., 2011). Necessary adaptative mechanisms are formed during that time (training cycle), and they give the possibility of reaching a high level of efficiency with a concurrent decrease in the risk of injuries (Fazio et al., 2011). The adaptative changes include, among other things, an increase in heart stroke volume, and as a consequence an increase in oxygen utilization in muscles
(Piccione et al., 2010). The cardiovascular system is exposed to modifications essential to ensure efficient transfer of oxygen and substrates to the muscles, and allowing removal of metabolites from them. Knowledge concerning physical effort is thus essential in making suitable decisions with regard to proper training strategy.

Analysis of selected plasma biochemical parameters could be useful in the prevention and early diagnosis of metabolic stress in horses (Trigo et al., 2010). Clinical and laboratory examinations also give the possibility to obtain information useful in evaluation of features affecting a horse's efficiency and its sport predispositions. They also allow for possible 
deficiencies and diseases to be detected, including those of subclinical course. The methods which allow for evaluation of a horse's progress in training involve, among other things, an analysis of physiological indices such as cardiac stress tests as well as examination of blood hematological and biochemical parameters (Piccione et al., 2008; Trigo et al., 2010; Bis-Wencel et al., 2012). Analyses of horse antioxidant status (Al-Qudah et al., 2006; Ogoński et al., 2010) and acidbase balance (Aguilera-Tejero et al., 2000) have additionally been performed in sport horses. Changes in lipid profile may be also a useful index in evaluation of training progress (Falaschin and Trombetta, 2001; Piccione et al., 2010).

Evaluation of particular parameters and changes in their reference ranges should be analyzed regarding particular disciplines as well as individually for each horse (Falaschin and Trombetta, 2001; Desgorces et al., 2008). It is significant that different changes observed in a system depend on the kind of exercise (Piccione et al., 2010; Vazzana et al., 2014). The knowledge and experience of the trainer play the most significant role in the selection of a suitable training strategy. One of the most important research tasks is to obtain new and useful information concerning those features which will enable an evaluation of the health status and training degree of the horses. This kind of research has been performed in jumping horses (Bis-Wence et al., 2012; Fazio et al., 2012; Vazzana et al., 2014) and for cross-country (Muñoz et al., 1999) and long-distance rides (Piccione et al., 2010; Trigo et al., 2010; Adamu et al., 2012).

The aim of this study was to evaluated the effect of training combined driving horses on particular blood hematological and biochemical parameters, acid-base balance as well as antioxidant status before and after training. The degree of driving horses' training was also evaluated based on the examined parameters.

\section{Materials and methods}

\subsection{Horses and training}

The study was performed on eight adult Polish Halfbred horses (Phb) aged 6-12 years. The horses took part in international competitions in combined driving disciplines, including dressage, marathon and obstacle driving. The study was conducted in starting season, in a period from March to October. The horses were fed three times a day with complete fodder ( $80 \%$ soaked oats, $10 \%$ barley, $10 \%$ maize) totalling $7 \mathrm{~kg} \mathrm{~d}^{-1}$. Two times a day the horses were given hay and silage $\left(3 \mathrm{~kg} \mathrm{~d}^{-1}\right)$. Moreover, the animals received sugar beet pulp in pellet form and wheat straw. All feed additives in the form of vitamins and electrolytes (Horse Vital Plus, electrolyte pellets, vitamin E + selenium mix, magnesium mix) were also dosed once a day, after exercise, according to manufacturer recommendations (during examinations after blood collection). The horses were additionally given
Humobentofet ${ }^{\circledR}$ (Tronina PHW, Poland) preparations once a day $\left(50 \mathrm{~g} \mathrm{~d}^{-1}\right)$.

The harnesses during training sessions were for four horses (mixed pairs, mares and geldings). The same marathon carriage was used each time. Each training session was performed in the morning hours (at 09:00) and lasted $2 \mathrm{~h}$. Endurance and speed were tested. The characteristics of the physical effort during training were as follows: walking $(1000 \mathrm{~m})$, trotting $(4000 \mathrm{~km})$, galloping $(500 \mathrm{~m})$, walking $(1000 \mathrm{~m})$ and trotting with four obstacles $(2000 \mathrm{~m})$. The exercises were performed each time in air temperatures of 10$20^{\circ} \mathrm{C}$.

\subsection{Blood sample collection and analysis}

All procedures applied in this study were approved by the 2nd Local Ethical Committee for Experiments on Animals in Wrocław (no. 55/2013). Blood for examinations was collected six times during the training season, each time about 2 weeks after competitions. Blood was collected from the external jugular vein (vena jugularis externa) under conditions which did not cause excessive stress to the animal: in the morning; in stud; before the training (sampling I); up to $5 \mathrm{~min}$ after the training (sampling II); and after a $30 \mathrm{~min}$ recovery period (sampling III), when the horses were washed and brought back to their boxes (18 blood samples were collected in total from each horse). Blood was collected in sterile test tubes (Sarsted, Poland) for serum $(10 \mathrm{~mL})$, in tubes with an anticoagulant (EDTA-K3; Sarsted, Poland), and anaerobically in $2 \mathrm{~mL}$ heparinized syringes (Pico 50, Radiometer; Copenhagen, Denmark) for gasometric examinations. Analyses of acid-base balance parameters were tested up to $15 \mathrm{~min}$ after blood collection, while hematological parameters were tested up to $2 \mathrm{~h}$ later. The blood samples for serum were centrifuged at $3000 \mathrm{~g}$ for $15 \mathrm{~min}$ at room temperature $(2 \mathrm{~h}$ after collection), and the serum samples were frozen $\left(-20^{\circ} \mathrm{C}\right)$ until analysis.

Hematological parameters analyses were performed using n ABC Vet analyzer (Horiba ABX, France), taking into account parameters such as red blood cells (RBC), white blood cells (WBC), platelets (PLT), hemoglobin (HGB), hematocrit (HCT), mean corpuscular volume, (MCV), mean corpuscular hemoglobin $(\mathrm{MCH})$ and mean corpuscular hemoglobin concentration (MCHC), lymphocytes (LYM), monocytes (MON) and granulocytes (GRA).

Laboratory analyses in blood serum were done using a Pentra 400 biochemical analyzer (Horiba ABX, France). The following parameters were estimated:

- glucose via oxidase method, HORIBA ABX reagents (glucose PAP, cat. no. A11A016979);

- lactic acid (LA) via the colorimetric method, HORIBA $\mathrm{ABX}$ reagents (cat. no. A11A01721); 
Table 1. Hematological parameters observed before and after training as well as after 30 min of rest (mean \pm standard deviation).

\begin{tabular}{lllll}
\hline Parameters & \multicolumn{3}{c}{ Sampling } & \\
\cline { 2 - 4 } & Before training & After training & 30 min rest & $P$ value \\
\hline RBC $\left(10^{12} \mathrm{~L}^{-1}\right)$ & $7.51 \pm 0.72^{\mathrm{A}}$ & $8.07 \pm 0.59^{\mathrm{B}}$ & $7.71 \pm 0.45^{\mathrm{A}}$ & 0.02 \\
HGB $\left(\mathrm{mmol}^{-1}\right)$ & $7.32 \pm 0.51^{\mathrm{A}}$ & $7.88 \pm 0.46^{\mathrm{B}}$ & $7.46 \pm 0.33^{\mathrm{A}}$ & 0.01 \\
HCT $\left(\mathrm{L} \mathrm{L}^{-1}\right)$ & $0.35 \pm 0.03$ & $0.38 \pm 0.02$ & $0.36 \pm 0.02$ & 0.18 \\
PLT $\left(10^{9} \mathrm{~L}^{-1}\right)$ & $137.19 \pm 72.38$ & $135.72 \pm 35.23$ & $139.44 \pm 41.26$ & 0.83 \\
MCV $(\mathrm{fL})$ & $46.90 \pm 2.21$ & $47.28 \pm 1.88$ & $46.81 \pm 2.18$ & 0.91 \\
MCH $\left(\mathrm{mmol} \mathrm{L}^{-1}\right)$ & $0.98 \pm 0.05$ & $0.98 \pm 0.04$ & $0.97 \pm 0.05$ & 0.10 \\
MCHC $(\mathrm{fmol})$ & $20.84 \pm 0.52$ & $20.66 \pm 0.42$ & $20.75 \pm 0.46$ & 0.52 \\
WBC $\left(10^{9} \mathrm{~L}^{-1}\right)$ & $6.93 \pm 1.49$ & $8.10 \pm 1.57$ & $7.77 \pm 1.81$ & 0.39 \\
LYM $\left(\times 10^{9} \mathrm{~L}^{-1}\right)$ & $1.93 \pm 0.60$ & $2.47 \pm 0.93^{\mathrm{A}}$ & $2.00 \pm 0.62^{\mathrm{B}}$ & 0.02 \\
MON $\left(\times 10^{9} \mathrm{~L}^{-1}\right)$ & $0.62 \pm 0.24$ & $0.81 \pm 0.44$ & $0.72 \pm 0.42$ & 0.30 \\
GRA $\left(\times 10^{9} \mathrm{~L}^{-1}\right)$ & $4.38 \pm 1.43$ & $4.70^{\mathrm{a}} \pm 1.83$ & $5.04 \pm 1.86^{\mathrm{b}}$ & 0.06 \\
\hline
\end{tabular}

a,b Significant differences between before and after exercise $(P<0.05)$.

A,B Significant differences between before and after exercise $(P<0.01)$

RBC: red blood cells; HGB: hemoglobin; HCT: hematocrit; PLT: platelets; MCV: mean corpuscular volume;

$\mathrm{MCH}$ : mean corpuscular hemoglobin concentration; MCHC: mean corpuscular hemoglobin; WBC: white blood

cells; LYM: lymphocytes; MON: monocytes; GRA: granulocytes.

- $\beta$-hydroxybutyrate acid (BHBA), nonesterified fatty acids (NEFA) via enzymatic method, Randox reagents, Ireland (RANBUT, cat. no. RB1007, and NEFA cat. no. FA 115);

- aspartate aminotransferase (AST), lactate dehydrogenase (LDH) and $\gamma$-glutamyltransferase (GGT) enzyme activity via kinetic method, HORIBA ABX reagents (cat. no. A11A01629, A11A01824, A11A01630);

- total bilirubin concentration via colorimetric method, HORIBA ABX (cat. no. A11A01639);

- total protein and albumin via colorimetric method, HORIBA ABX (cat. no. A11A01669, A11A01664);

- $\mathrm{Ca}$, inorganic $\mathrm{P}$ and $\mathrm{Mg}$ via colorimetric method, HORIBA ABX (cat. no. A11A01633, A11A01665, A11A01646)

- $\mathrm{Cl}, \mathrm{Na}$ and $\mathrm{K}$ using an ion-selective adapter to Pentra 400 analyzer,

- glutathione peroxidase activity (GPx) via colorimetric method, Randox reagents (cat. no. Ransel RS 505).

Analysis of parameters determining acid-base balance was performed according to methodology of blood gasometric examinations. In order to determine the acid-base balance, the following parameters were analyzed using VetStat $^{\mathrm{TM}}$ (Idexx, USA): $\mathrm{pH}$, partial pressure of carbon dioxide $\left(p \mathrm{CO}_{2}\right)$, total carbon dioxide $\left(\mathrm{TCO}_{2}\right)$, concentration of bicarbonates $\left(\mathrm{HCO}_{3}^{-}\right)$and extracellular base excess (BE).

Anion gap (AG) was calculated according to the following formula:

$\mathrm{AG}=\left(\left[\mathrm{Na}^{+}\right]+\left[\mathrm{K}^{+}\right]\right)-\left(\left[\mathrm{HCO}_{3}^{-}\right]+\left[\mathrm{Cl}^{-}\right]\right)$.
Measurements of heart rate (HR) and respiratory rate (RR) were made using the auscultatory method at the same times as when blood was collected for analysis.

\subsection{Statistical analysis}

All the results were expressed as means and standard deviation, and all variables were tested for normality using the Shapiro-Wilk test. The data obtained were subjected to analysis of variance (ANOVA) using a linear model procedure of Statistica v10. The statistical model was as follows:

$Y i j=\mu+\alpha i+\varepsilon i j$,

where $Y i j$ is the dependent variable; $\mu$ is the overall mean; $\alpha i$ is the effect of blood sampling before training, directly after training and after a 30 min rest $(i=1,2,3)$; and $\varepsilon i j$ is the random residual error.

The differences among treatment means were tested for significance using post hoc comparisons accomplished via Duncan's multiple range test. Effects were considered significant at a probability of $P<0.05$.

\section{Results}

A significant $(P<0.01)$ post-exercise increase was noted in HR (from 32.6 to 86.4 beats $\mathrm{min}^{-1}$ ) and RR (from 14.3 to $\left.68.6 \mathrm{~min}^{-1}\right)$. A decrease in $\mathrm{HR}$ and $\mathrm{RR}$ was significant $(P<0.01)$ after rest time.

Mean values of blood hematological indices in horses are presented in Table 1. Significant $(P<0.01)$ differences were noted between rest and post-exercise levels of RBC and HGB. These parameters showed a decrease after $30 \mathrm{~min}$ $(P<0.01)$. Similar dynamics was noted in the case of HCT, 
Table 2. Parameters of acid-base balance and concentration of selected macroelements and electrolytes before and after horses' training (mean \pm standard deviation).

\begin{tabular}{llllr}
\hline Parameters & \multicolumn{3}{c}{ Sampling } & \\
\cline { 2 - 4 } & Before training & After training & 30 min rest & $P$ value \\
\hline $\mathrm{pH}$ & $7.41 \pm 0.04$ & $7.45 \pm 0.61$ & $7.41 \pm 0.03$ & 0.54 \\
$\mathrm{TCO}_{2}\left(\mathrm{mmol} \mathrm{L}^{-1}\right)$ & $30.72 \pm 1.48^{\mathrm{a}}$ & $31.01 \pm 1.15^{\mathrm{A}}$ & $29.89 \pm 1.37^{\mathrm{Bb}}$ & 0.01 \\
$p \mathrm{CO}_{2}\left(\mathrm{kPa}^{-}\right.$ & $6.65 \pm 0.76$ & $6.18 \pm 0.51$ & $6.43 \pm 0.5$ & 0.14 \\
$\mathrm{HCO}_{3}^{-}\left(\mathrm{mmol} \mathrm{L}^{-1}\right)$ & $29.17 \pm 1.35^{\mathrm{a}}$ & $28.34 \pm 1.31^{\mathrm{bA}}$ & $29.51 \pm 1.09^{\mathrm{B}}$ & $<0.01$ \\
$\mathrm{BE}\left(\mathrm{mmol} \mathrm{L}^{-1}\right)$ & $3.87 \pm 1.27^{\mathrm{A}}$ & $3.22 \pm 1.41^{\mathrm{A}}$ & $5.04 \pm 1.05^{\mathrm{B}}$ & $<0.01$ \\
$\mathrm{Ca}\left(\mathrm{mmol} \mathrm{L}^{-1}\right)$ & $3.05 \pm 0.2^{\mathrm{A}}$ & $3.06 \pm 0.18^{\mathrm{a}}$ & $3.15 \pm 0.16^{\mathrm{Bb}}$ & 0.02 \\
$\mathrm{P}\left(\mathrm{mmol} \mathrm{L}^{-1}\right)$ & $0.98 \pm 0.24$ & $1.11 \pm 0.31$ & $1.01 \pm 0.29$ & 0.13 \\
$\mathrm{Mg}\left(\mathrm{mmol} \mathrm{L}^{-1}\right)$ & $0.78 \pm 0.08^{\mathrm{Aa}}$ & $0.74 \pm 0.07^{\mathrm{b}}$ & $0.73 \pm 0.08^{\mathrm{B}}$ & 0.01 \\
$\mathrm{Na}\left(\mathrm{mmol} \mathrm{L}^{-1}\right)$ & $147.63 \pm 8.37$ & $148.86 \pm 8.24$ & $149.08 \pm 8.18$ & 0.50 \\
$\mathrm{~K}\left(\mathrm{mmol} \mathrm{L}^{-1}\right)$ & $4.11 \pm 2.08$ & $4.35 \pm 1.90$ & $3.41 \pm 2.22$ & 0.31 \\
$\left.\mathrm{Cl}^{-1} \mathrm{mmol} \mathrm{L}^{-1}\right)$ & $106.81 \pm 4.65$ & $105.92 \pm 4.55$ & $107.71 \pm 5.05$ & 0.79 \\
$\mathrm{AnGap}\left(\mathrm{mmol} \mathrm{L}^{-1}\right)$ & $15.07 \pm 4.51$ & $17.66 \pm 4.35$ & $16.39 \pm 3.53$ & 0.09 \\
\hline a,b Significant differences between before and after exercise $(P<0.05)$. & & \\
$\mathrm{A}, \mathrm{B}$ Significant differences between before and after exercise $(P<0.01)$. & & \\
$\mathrm{TCO}$ : total carbon dioxide; $p \mathrm{CO}_{2}$ : partial pressure of $\mathrm{CO}_{2} ; \mathrm{HCO}_{3}^{-}$bicarbonate; $\mathrm{BE}$ base excess; AnGap: anion \\
gap.
\end{tabular}

MCV and WBC; however, the differences were not statistically significant. The lymphocyte count after training showed a distinct increase, and after the $30 \mathrm{~min}$ recovery period this value decreased $(P<0.01)$ to a level close to that of rest. The changes in red-cell-related indices, despite some fluctuations, were not confirmed statistically. The granulocyte count increased gradually during the research period, and the values noted between the end of training and collection after 30 min differed significantly $(P<0.05)$. Parameters such as HGB, HCT and MCV to the highest degree obtained their baseline values after the 30 min recovery period.

The values of horses' blood gasometric parameters before the training demonstrated the acid-base balance state (Table 2). After the end of the training, the values of $\mathrm{TCO}_{2}$ and $p \mathrm{CO}_{2}$ showed an increase (not confirmed statistically). The level of $\mathrm{HCO}_{3}^{-}$increased after the training $(P<0.05)$. Base excess showed a significant increase $(P<0.01)$, like $\mathrm{HCO}_{3}^{-}$ in the recovery period. As a consequence, blood $\mathrm{pH}$ recovered to its rest value after the training, and a decrease in $\mathrm{TCO}_{2}$ was noted after the recovery period $(P<0.01)$.

In the case of the examined macroelements, only Mg concentration showed a significant decrease after the rest time $(P<0.05)$, while $\mathrm{Ca}$ concentration increased significantly $(P<0.01)$ compared to the rest value. The changes in electrolytes directly after training were not statistically significant (Table 2).

Blood glucose concentration increased just after the training $(P<0.01)$ and thereafter decreased to below the rest values $(P<0.01)$. A similar trend was noted in the case of LA concentration (Table 3). Intensification of lipolysis was observed directly after the training and was reflected in a NEFA concentration increase $(P<0.01)$. A NEFA decrease

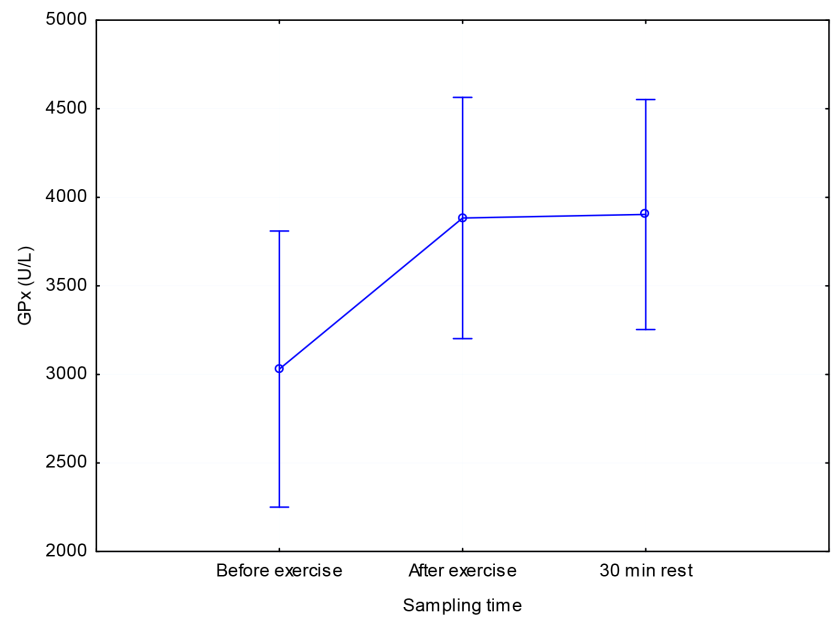

Figure 1. Changes in glutathione peroxidase (GPx) activity during the training period $(P=0.25)$.

was in turn significant $(P<0.01)$ after the rest. The concentrations of TP, albumin, CK, AST, LDH, and GGT experienced similar changes, but these changes were not confirmed statistically. The changes in total bilirubin concentration (growth after the training) were, however, confirmed statistically $(P<0.05)$.

The changes in GPx activity were not confirmed statistically, but an increasing tendency after training was noted (Fig. 1). 
Table 3. Concentration of biochemical parameters and enzyme activity before training, after training and after a $30 \mathrm{~min}$ rest period (mean \pm standard deviation).

\begin{tabular}{|c|c|c|c|c|}
\hline \multirow[t]{2}{*}{ Parameters } & \multicolumn{3}{|c|}{ Sampling } & \multirow[b]{2}{*}{$P$ value } \\
\hline & Before training & After training & 30 min rest & \\
\hline GLU $\left(\mathrm{mmol} \mathrm{L}^{-1}\right)$ & $5.34 \pm 0.75^{\mathrm{A}}$ & $5.74 \pm 0.75^{\mathrm{B}}$ & $4.90 \pm 0.58^{\mathrm{C}}$ & $<0.01$ \\
\hline $\mathrm{LA}\left(\mathrm{mmol} \mathrm{L}^{-1}\right)$ & $1.52 \pm 0.73$ & $2.60 \pm 0.55$ & $1.56 \pm 0.47$ & 0.02 \\
\hline BHBA $\left(\mathrm{mmol} \mathrm{L}^{-1}\right)$ & $0.17 \pm 0.07$ & $0.13 \pm 0.07$ & $0.16 \pm 0.07$ & 0.60 \\
\hline NEFA $\left(\mathrm{mmol} \mathrm{L}^{-1}\right)$ & $0.07 \pm 0.03^{\mathrm{A}}$ & $0.77 \pm 0.32^{\mathrm{B}}$ & $0.28 \pm 0.17^{\mathrm{C}}$ & $<0.01$ \\
\hline $\mathrm{CK}\left(\mathrm{UL}^{-1}\right)$ & $198.26 \pm 47.77$ & $231.39 \pm 25.10$ & $202.61 \pm 42.35$ & 0.64 \\
\hline $\mathrm{TP}\left(\mathrm{gL}^{-1}\right)$ & $64.00 \pm 3.48$ & $67.12 \pm 4.06$ & $65.32 \pm 4.65$ & 0.79 \\
\hline Alb. $\left(\mathrm{g} \mathrm{L}^{-1}\right)$ & $31.52 \pm 1.34$ & $33.57 \pm 1.55$ & $32.26 \pm 1.45$ & 0.19 \\
\hline $\operatorname{AST}\left(\mathrm{UL}^{-1}\right)$ & $314.35 \pm 47.77$ & $344.70 \pm 60.21$ & $334.26 \pm 38.46$ & 0.53 \\
\hline GGT $\left(\mathrm{UL}^{-1}\right)$ & $18.35 \pm 11.23$ & $21.68 \pm 12.28$ & $19.11 \pm 12.19$ & 0.96 \\
\hline $\mathrm{LDH}\left(\mathrm{UL}^{-1}\right)$ & $516.48 \pm 95.07$ & $583.99 \pm 99.49$ & $539.47 \pm 100.06$ & 0.85 \\
\hline Bilirubin $(\mu \mathrm{mol} \mathrm{L}-1)$ & $28.58 \pm 13.04^{\mathrm{a}}$ & $35.38 \pm 11.72^{b}$ & $30.91 \pm 9.28$ & 0.14 \\
\hline
\end{tabular}

a,b Significant differences between before and after exercise $(P<0.05)$.

A,B,C Significant differences between before and after exercise $(P<0.01)$.

GLU: glucose; LA: lactic acid; BHBA: $\beta$-hydroxybutyrate acid; NEFA: nonesterified fatty acids; CK: creatinine; TP: total protein; Alb: albumin; AST: aspartate aminotransferase; GGT: $\gamma$-glutamyltransferase; LDH: lactate dehydrogenase.

\section{Discussion}

The changes in HR and RR reflect the oxygen demand of working muscles. These parameter changes result from the type of activity and its duration as well as cycles and individual horse variability (Krumrych, 2010; Zobba et al., 2011). Post-exercise heart rate recovery times revealed that the horses were well trained and exhibited a good physiological response to intense exercise.

Correct preparation of the horses for particular sporting disciplines should ensure fast recovery of blood indices to suitable levels after the rest period (Al-Qudah et al., 2006; Trigo et al., 2010). Environmental conditions (high temperature and humidity) are the most significant factors affecting the physical capacity. The present study was conducted under temperatures ranging from 10 to $20^{\circ} \mathrm{C}$, which was neutral for the horses' metabolism.

Irrespective of the degree of effort and training, adaptative changes occur in a horse's body system causing RBC level increase. During the physical effort, RBCs and their reserves may be conditioned by age and degree of training (Bis-Wencel et al., 2011). Only a small RBC increase was noted in this study, whereas Piccione et al. $(2008,2010)$ obtained a higher post-exercise RBC increase in racing horses. The same authors also point to a significant relationship between RBC increase and blood catecholamine level. Catecholamines stimulate secretion activity of the spleen. RBC count changes depend on the duration of physical effort and its degree (Piccione et al., 2008). Also, dehydration observed after the training is related to an increase in red blood cell count. A similar reaction is observed in the case of other erythrocyte-related parameters, i.e., HTC and HGB. An in- crease in HTC and HGB facilitates oxygen transport and increases blood buffer capacity and thus exercise capacity (Jones, 2005; Piccione et al., 2010). Especially high values of these parameters have been noted in horses with increased blood transport capacity (Piccione et al., 2008; Tateo et al., 2008).

Like in the case of red cells, the spleen is responsible for the increase in WBC level in peripheral vesicles (Piccione et al., 2008, 2010; Vazzana et al., 2014). A post-exercise increase in white blood cell count was observed in this study. Leukocytosis may be related to the change in number of neutrophils and lymphocytes (Adamu et al., 2012). A postexercise decrease in granulocytes count was noted in this study; however an increase was observed in the case of lymphocytes. This confirms the observations of Piccione et al. (2010), who interpret such an occurrence as a quick response to stress in the horses' systems. In turn, in the study performed on endurance horses, age did not demonstrate any distinct effect on physical, hematological and biochemical parameters (Adamu et al., 2013).

According to Hanzawa et al. (1995), a decrease in MCV and MCHC level usually accompanies light exercise. Greater physical effort in turn causes an increase in the level of these parameters. A low, post-exercise MCV increase and a MCHC decrease were noted in this study. Another tendency was observed by Muñoz et al. (2008) for racing and driving horses; they observed post-exercise decrease in MCV values, which may be explained by the fact that erythrocytes accumulated in the spleen are smaller. The occurrence of an MCV decrease was also related to the increase in the level of blood catecholamines (Muñoz et al., 2008). Depending on the intensity, training leads to the changes in blood acid-base 
balance, which may be taken into account in estimation of metabolic and respiratory changes. Exercising horses often show a tendency towards both metabolic acidosis (due to the accumulation of lactate) and respiratory alkalosis (as a consequence of hyperventilation) (Aguilera-Tejero et al., 2000). A small decrease in $\mathrm{BE}$ level and $\mathrm{HCO}_{3}^{-}$concentration in blood was observed in this study directly after training. A decrease in $\mathrm{HCO}_{3}^{-}$concentration is also attributed to LA increase (Aguilera-Tejero et al., 2000). A BE $(P<0.01)$ and $\mathrm{HCO}_{3}^{-}$increase was noted after the recovery period. These changes were a result of a compensation effect of $p \mathrm{CO}_{2}$ changes. A similar range in metabolic component changes was noted in jumping horses after training (Aguilera-Tejero et al., 2000). A $\mathrm{HCO}_{3}^{-}$decrease after training could be explained by hyperventilation, which makes a massive expulsion of $\mathrm{CO}_{2}$ from the lungs possible, so that the conversion of $\mathrm{CO}_{2}$ into $\mathrm{HCO}_{3}^{-}$cannot occur (Fazio et al., 2012).

The intensity of the training performed in this study does not point to an excessive $\mathrm{H}^{+}$accumulation. Short exercises with lower intensity, e.g., jumping, also do not lead to lactic acidosis (Aguilera-Tejero et al., 2000), while highintensity exercise leads to metabolic acidosis (Waller and Lindinger, 2005; Vazzana et al., 2014). There are distinct changes in acid-base balance, and the complete recovery of many parameters that determine acid-base status requires 60-120 min. The results of this study show that training load did not cause any disturbances in acid-base balance, with visible compensation in the recovery period.

When comparing the concentrations of $\mathrm{Na}, \mathrm{K}, \mathrm{Cl}$ and $\mathrm{Ca}$ obtained in this study to the results of endurance horses (Adamu et al., 2013), large differences concerning the breed and type of training may be observed. No differences were noted in electrolyte concentration $(\mathrm{Na}, \mathrm{K}, \mathrm{Cl})$ in blood of endurance horses that were eliminated from competitions compared with those that successfully completed the competitions (Fielding et al., 2009). High electrolyte losses are usually noted in poorly trained horses, which get tired easily. High chlorine losses cause weakening of muscles and dehydration. Electrolyte loss may be also related to temperature.Concentrations of $\mathrm{Na}$ and $\mathrm{K}$ in blood increased during moderate-intensity and short-duration exercises of jumping horses, while $\mathrm{Cl}$ showed an insignificant decrease (AguileraTejero et al., 2000). A decreasing tendency of $\mathrm{Na}$ and $\mathrm{Cl}$ as a result of sweating has been demonstrated in most of the studies conducted so far (Muñoz et al., 2008).

A increase in total proteins during training shown in the present study reflects the redistribution of fluid and electrolytes from the vascular compartment to the tissue extracellular fluid that is known to occur during physical activity (Fazio et al., 2011).

Lactate concentration in blood is a marker of anaerobic and aerobic thresholds during exercise for horses (Campbell, 2011; Adamu et al., 2013). In horses, a concentration of lactate in blood of $4 \mathrm{mmol} \mathrm{L}^{-1}$ has been arbitrarily used to compare the fitness of animals before and after a train- ing period and to develop training protocols. It should also be taken into account that an increase in lactate concentration in blood may result from poor glucose uptake by the metabolizing tissues (Campbell, 2011). It was demonstrated in a study conducted on Thoroughbreds horses that ran on the treadmill that maximal lactate steady state (maxLASS) within the aerobic-anaerobic threshold should be accepted at a level considerably below $4 \mathrm{mmol} \mathrm{L}^{-1}$ (Lindner, 2010). This study shows that LA level after endurance and speed training is $2.60 \mathrm{mmol} \mathrm{L}^{-1}$. This also confirms the necessity of an acceptance of lower LA levels in aerobic-anaerobic threshold interpretation. Despite the test maxLASS being a gold standard for determining aerobic capacity, it was observed in a recent study that it may be replaced by a more precise LMS test - lactate minimum speed (Miranda et al., 2014). In other training systems, cessation of low work intensity is related to an immediate decrease in blood LA concentration (Campbell, 2011).

Glucose concentration in horse blood during training is subject to changes depending on intensity and duration of the exercises. Plasma glucose concentration increased progressively during exercise, peaking at the end (Geor et al., 2002). The exercise-associated increase in hepatic glucose output is mainly mediated through a decrease in the insulin : glucagon ratio (Geor et al., 2000). The endurance horses that exhibited good performance were able to utilize glucose more effectively than those that showed poor performance (Adamu et al., 2010).

Nonesterified fatty acids concentration in horses before exercise was always below $200 \mu \mathrm{mol} \mathrm{L}^{-1}$ (Lindner et al., 2009). The NEFA in plasma of the horses increased after all exercise types applied. In the case of training lasting $45 \mathrm{~min}$ at $V_{2.5}$, an increase in plasma-free fatty acids was from 99 to $642 \mu \mathrm{mol} \mathrm{L}^{-1}$ in the first training session, and from 64 to $673 \mu \mathrm{mol} \mathrm{L}{ }^{-1}$ in the 21 st training session (Lindner et al., 2009). There are some opinions that, in horses trained for long distances, NEFA may, at the conclusion of a race, provide as much as $90 \%$ of the total energy requirements (Piccione et al., 2010). The present study shows that longterm endurance exercises in driving horses cause considerable lipomobilization.

There are a range of biochemical markers of exercise effects on muscles; one of these is CK, which should not exceed $200 \mathrm{UL}^{-1}$ (Ostaszewski et al., 2012). Increased serum $\mathrm{CK}$ activity is used as an indicator of muscle damage or injury. A gradual increase in AST and CK activity was noted in Thoroughbreds up to the 60th day of training, and then a decrease at the end of the training period (Fazio et al., 2011). A moderate increase in AST and CK activity noted in this study after the training could have been caused by the normal enzyme response to exercise, causing a transient alteration in the cell membrane permeability. Another study demonstrated that the elevated levels of creatinine and AST after a moderate training exercise period were the only exceptions (BisWencel et al., 2012). In racing horses, the activity of enzymes 
(AST, CK) is directly associated with the distance covered (Trigo et al., 2010). In the case of young horses, rest plasma LDH, CK and AST activity was probably attributable to age, and was not correlated with the training progress (Tateo et al., 2008). AST activity is noted in numerous tissues; therefore AST is less specific for the muscles than CK. A post-training AST activity increase is related to either overt damage or a change in the muscle fiber membrane, causing a transient increase in permeability (Ostaszewski et al., 2012).

Adamu et al. (2014) noted that decreased GGT activity could be associated with the decreased glucose uptake by the skeletal muscles in endurance horses showing poor performance. GGT may also be involved in generating free radicals. Serum GGT activity has been used as a marker for liver diseases, and a series of epidemiological studies have suggested that serum GGT within its normal range might be an enzyme associated with oxidative stress.

Exercise itself has been shown to induce pulmonary oxidative stress in horses and human athletes and can therefore further increase the pulmonary oxidant-antioxidant disequilibrium in trained horses. Training might positively influence the antioxidant capacity of the horse. Indeed, an increase in different antioxidants, such as vitamin C, GPx and SOD, has been observed in Standardbreds (de Moffarts et al., 2004). A serum GPx increase was noted directly after intensive training (Williams and Carlucci, 2006; Krumrych, 2010). Similar relationships were observed in this study, where a further increase was noted $30 \mathrm{~min}$ post-training. It is alleged that a post-exercise decrease in GPx activity can be an indication of oxidative stress and may suggest its inactivation, resulting in excessive production of reactive oxygen species. A study by Krumrych (2010) demonstrated that mobilization of antioxidant mechanisms depends on intensity, type and duration of horses' exertion, and activity of GPx showed high post-exercise changeability, which suggests the great importance of this enzyme in the protection of the horse's system from the increased generation of reactive oxygen species.

In conclusion, the results of the present study demonstrate that examined hematological and biochemical blood parameters enable an evaluation of physical preparation for exertion and training intensity of driving horses. Significant post-training changes $(P<0.01)$ in parameters such as RBC, HGB, GLU and NEFA were noted. The fastest recovery to the rest values was observed in the case of RBC, HGB, LYM, $\mathrm{TCO}_{2}, \mathrm{HCO}_{3}^{-}$, GLU and NEFA. Despite some tendencies, other changes were not confirmed statistically. The present study shows that long-term endurance exercises in driving horses cause considerable lipomobilization. In the case of driving horses' training, there is a need to accept lower LA values in aerobic-anaerobic threshold interpretation. The design of the exercises did not cause acid-base balance disturbances, with visible compensation in the recovery period. The observed fluctuations in blood parameter values show a properly performed and selected training program, which should be taken into account by horses' trainers and concen- tration of parameters in blood such as AST, CK, NEFA and lower lactate threshold.

Acknowledgements. This work was supported within the framework of Statutory Researches of Wroclaw University of Environmental and Life Sciences, no. BIHZ/909/2013/13.

Edited by: A.-E. Freifrau von Tiele-Winckler

Reviewed by: two anonymous referees

\section{References}

Adamu, L., Adzahan, N. M., Abdullah, R., and Ahmad, B.: Effects of race distance on physical, hematological and biochemical parameters of endurance horses, Am. J. Anim. Vet. Sci., 5, 244248, 2010.

Adamu, L., Adzahan, N. M., Abdullah, R., and Ahmad, B.: Changes in biochemical, hematological and cytokine in endurance horses with metabolic crises, J. Anim. Vet. Advan., 11, 3431-3436, 2012.

Adamu, L., Adzahan, N. M., Abdullah, R., and Ahmad, B.: Effect of age and performance on physical, hematological, and biochemical parameters in endurance horses, J. Equine Vet. Sci., 33, 415420, 2013.

Adamu, L., Adzahan, N. M., Rasedee, A., and Ahmad, B.: Responses of serum biochemical parameters, electrolytes and heart rate in an $80 \mathrm{~km}$ endurance race, J. Vet. Adv., 4, 329-337, 2014.

Aguilera-Tejero, E., Estepa, J. C., López, I., Bas, S., Mayer-Valor, R., and Rodríguez, M.: Quantitative analysis of acid-base balance in show jumpers before and after exercise, Res. Vet. Sci., 68, 103-108, 2000.

Al-Qudah, K. M. and Al-Majali, A. M.: Status of biochemical and antioxidant variables in horses before and after long distance race, Revue Méd. Vét., 157, 307-312, 2006.

Bis-Wencel, H., Lutnicki, K., Rowicka, A. Z., and Bryl, M.: Longterm exercise and its effect on selected hematological parameters of blood in horses, Med. Weter., 67, 418-421, 2011.

Bis-Wencel, H., Lutnicki, K., Rowicka, A. Z., Nowakowicz-Dębek, B., and Bryl, M.: Effort of varying intensity as a factor influencing the variability of selected biochemical blood parameters of jumping horses, B. Vet. I. Pulawy, 56, 225-229, 2012.

Campbell, E. H.: Lactate-driven equine conditioning programmes, Vet. J., 190, 199-207, 2011.

de Moffarts, B., Kirschvink, N., Art, T., Pincemail, J., Michaux, C., Cayeux, K., Defraigne, J. O., and Lekeux, P.: Impact of training and exercise intensity on blood antioxidant markers in healthy Standardbred horses, Equine Comp. Exerc. Physio., 1, 211-220, 2004.

Desgorces, F. D., Testa, M., and Petibois, C.: Training-level induced changes in blood parameters response to on-water rowing races, J. Sport. Sci. Med., 7, 425-430, 2008.

Falaschini, A. and Trombetta, M. E.: Modifications induced by training and diet in some exerciserelated blood parameters in young trotters, J. Equine Vet. Sci., 21, 601-604, 2001.

Fazio, F., Assenza, A., Tosto, F., Casella, F., Piccione, G., and Caola, G.: Training and haematochemical profile in Thoroughbreds and standardbreds: A longitudinal study, Livest. Sci., 141, 221-226, 2011. 
Fazio, F., Messina, V., Casella, S., Giannetto, C., Marafioti, S., and Piccione, G.: Effect of a simulate show jumping competition on the blood gas profile of horses trained for show jumping, Turk. J. Vet. Anim. Sci., 36, 259-265, 2012.

Fielding, C. L., Magdesian, K. G., Rhodes, D. M., Meier, C. A., and Higgins, J. C.: Clinical and biochemical abnormalities in endurance horses eliminated from competition for medical complications and requiring emergency medical treatment: 30 cases (2005-2006), J. Vet. Emerg. Crit. Car., 19, 473-478, 2009.

Geor, R. J., Hinchcliff, K. W., and Sams, R. A.: $\beta$-Adrenergic blockade augments glucose utilization in horses during graded exercise, J. Appl. Physiol., 89, 1086-1098, 2000.

Geor, R. J., McCutcheon, L. J., Hinchcliff, K. W., and Sams, R. A.: Training-induced alterations in glucose metabolism during moderate-intensity exercise, Equine Vet. J., Suppl., 34, 22-28, 2002.

Hanzawa, K., Kubo, K., Kai, M., Hiraga, A., and Watanabe, S.: Effects of exercise on erythrocytes in normal and splenectomised Thoroughbred horses, Equine Vet. J., Suppl., 18, 439-442, 1995.

Jones, E. W.: Scientific training, J. Equine Vet. Sci., 25, 320-321, 2005.

Krumrych, W.: Blood antioxidant defence in horses during physical exercises, B. Vet. I. Pulawy, 54, 617-624, 2010.

Lindner, A. E.: Maximal lactate steady state during exercise in blood of horses, J. Anim. Sci., 88, 2038-2044, 2010.

Lindner, A., Mosen, H., Kissenbeck, S., Fuhrmann, H., and Sallmann, H. P.: Effect of blood lactate-guided conditioning of horses with exercises of differing duration and intensities on heart rate and biochemical blood variables, J. Anim. Sci., 87, 3211-3217, 2009.

Miranda, M. C. P. C., Queiroz-Neto, A., Silva-Júnior, J. R., Pereira, M. C., Soares, O. A. B., Borghi, R. T., and Ferraz, G. C.: Comparison of the lactate minimum speed and the maximal lactate steady state to determine aerobic capacity in purebred Arabian horses, New Zeal. Vet. J., 62, 15-20, 2014.

Muñoz, A., Riber, C., Santisteban, R., Rubio, M. D., and Agüera, E. I.: Cardiovascular and metabolic adaptations in horses competing in cross-country events, J. Vet. Med. Sci., 61, 13-20, 1999.

Muñoz, A., Riber, C., Trigo, P., and Castejón, F.: Erythrocyte indices in relation to hydration and electrolytes in horses performing exercises of different intensity, Comp. Clin. Pathol., 17, 213$220,2008$.
Ogoński, T., Pikuła, R., and Kopczyński, P.: Wplyw wysilku fizycznego na wartosc wybranych wskaznikow hematologicznych $\mathrm{i}$ antyoksydacyjnych $\mathrm{u}$ koni bedacych $\mathrm{w}$ roznych okresach treningu. [The influence of the physical effort on the value of chosen haematologic and antioxidative indicators in horses being in different phases of the training], Acta Sci. Pol. Zootech., 9, 173-180, 2010.

Ostaszewski, P., Kowalska, A., Szarska, E., Szpotański, P., Cywinska, A. P., Bałasinska, B., and Sadkowski, T.: Effects of Bhydroxy- $\beta$-methylbutyrate and $\gamma$-oryzanol on blood biochemical markers in exercising Thoroughbred race horses, J. Equine Vet. Sci., 32, 542-551, 2012.

Piccione, G., Vazzana, I., Gianetto, C., Gianesella, M., and Ferrantelli, V.: Modification of some haematological and haematochemical parameters in horse during long distance rides, J. Vet. Sci., 1, 37-43, 2008.

Piccione, G., Casella, C., Gianetto, C., Messina, V., Monteverde, V., Caola, G., and Guttadauro, S.: Haematological and haematochemical responses to training and competition in standardbred horses, Comp. Clin. Pathol., 19, 95-101, 2010.

Tateo, A., Valle, E., Padalino, B., Centoducati, P., and Bergero, D.: Change in some physiologic variables induced by Italian traditional conditioning in standardbred yearling, J. Equine Vet. Sci., 28, 743-750, 2008.

Trigo, P., Castejon, F., Riber, C., and Muñoz, A.: Use of biochemical parameters to predict metabolic elimination in endurance rides, Equine Vet. J., 42, Suppl., 38, 142-146, 2010.

Waller, A. and Lindinger, M. I.: Physicochemical analysis of acidbase status during recovery from high-intensity exercise in Standardbred racehorses, Equine Com. Exercise Physiol., 2, 119127, 2005.

Williams, C. A. and Carlucci, S.: Oral vitamin E supplementation on oxidative stress, vitamin and antioxidant status in intensely exercised horses, Equine Vet. J., 38, Suppl. 36, 617-621, 2006.

Vazzana, I., Rizzo, M., Dara, S., Niutta, P. P., Giudice, E., and Piccione, G.: Haematological changes following reining trials in quarter horses, Acta Sci. Vet., 42, 1171, 2014.

Zobba, R., Ardu, M., Niccolini, S., Cubeddu, F., Dimauro, C., Bonelli, P., Dedola, C., Visco, S., and Parpaglia, M. L. P.: Physical, Hematological, and Biochemical Responses to Acute Intense Exercise in Polo Horses, J. Equine Vet. Sci., 31, 542-548, 2011. 